\title{
Actividad antibacteriana de extractos metanólicos de pepino de mar (Pattalus mollis) frente a bacterias patógenas
}

\author{
Antibacterial activity of methanolic extracts from sea cucumber (Pattalus mollis) \\ against pathogenic bacteria \\ Katia Díaz-Sol Sol ${ }^{1}$, Claudia Sánchez-Robinet ${ }^{1}$, Carlos Pariona V. ${ }^{2}$, \\ Pablo Londoñe-Bailon ${ }^{1,3}$
}

\section{Resumen}

\begin{abstract}
El objetivo de esta investigación fue evaluar la actividad antibacteriana de extractos de metanol y metanol-cloroformo de tegumento, gónada y víscera de Pattalus mollis. Se recolectaron 50 especímenes en la bahía de Pucusana, Perú, se diseccionaron longitudinalmente por la zona ventral del tegumento y se retiraron los órganos internos (víscera, gónada). Las muestras fueron secadas hasta un $10 \%$ de humedad, molidas y almacenadas en congelación. Los extractos fueron obtenidos mediante maceración empleando metanol y cloroformo. La evaluación in vitro se realizó mediante el método de microdilución en caldo, los extractos se diluyeron en siete concentraciones $(3.9-250 \mathrm{mg} / \mathrm{ml})$ y evaluados frente a Pseudomonas aeruginosa ATCC 27853, Staphylococcus aureus ATCC 14775 y Vibrio alginolyticus ATCC 17749. Los extractos metanólicos presentaron inhibición bacteriana frente a las tres bacterias demostrando poseer un efecto bactericida y bacteriostático contra bacterias grampositivas y gramnegativas. Los extractos de víscera, gónada y tegumento presentaron una concentración mínima inhibitoria (CMI) de $62.5 \mathrm{mg} / \mathrm{ml}$ o más frente a $P$. aeruginosa, $V$. alginolyticus y $S$. aureus. Los resultados sugieren que el pepino de mar $P$. mollis, proveniente de las costas peruana, es un candidato novedoso para la obtención de compuestos antibacterianos.
\end{abstract}

Palabras clave: pepino de mar; Pattalus mollis; extracto metanólico; actividad antibacteriana

${ }^{1}$ Laboratorio de Biotecnología, Dirección de Investigación, Desarrollo, Innovación y Transferencia Tecnológica, Instituto Tecnológico de la Producción (ITP), Callao, Perú

${ }^{2}$ Instituto Tecnológico de la Producción, Callao, Perú

${ }^{3}$ E-mail: plondone@itp.gob.pe

Recibido: 18 de diciembre de 2018

Aceptado para publicación: 15 de julio de 2019 
The aim of this study was to evaluate the antibacterial activity of methanol and methanol-chloroform extracts of tegument, gonad and viscera of Pattalus mollis. Fifty specimens were collected in the Pucusana Bay, Peru, dissected longitudinally through the ventral area of the tegument and the internal organs (viscera, gonad) were removed. The samples were dried to $10 \%$ moisture, milled and stored in freezing. The extracts were obtained by maceration using methanol and chloroform. The in vitro evaluation was performed using the broth microdilution method, the extracts were diluted in seven concentrations $(3.9-250 \mathrm{mg} / \mathrm{ml})$ and evaluated against Pseudomonas aeruginosa ATCC 27853, Staphylococcus aureus ATCC 14775 and Vibrio alginolyticus ATCC 17749. The methanol extract showed bacterial inhibition against the three bacteria, demonstrating a bactericidal and bacteriostatic effect against Gram-positive and Gram-negative bacteria. The viscera, gonad and tegument extracts showed a minimum inhibitory concentration (MIC) of $62.5 \mathrm{mg} / \mathrm{ml}$ or higher against P. aeruginosa, V. alginolyticus and S. aureus. The results suggest that sea cucumber $P$. mollis, from the Peruvian coasts, is a novel candidate to produce antibacterial compounds.

Key words: sea cucumber; Pattalus mollis; methanolic extract; antibacterial activity

\section{INTRODUCCIÓN}

La resistencia bacteriana ha impulsado la búsqueda de nuevos compuestos bioactivos que poseen actividad antibacteriana. El océano alberga una gran cantidad de organismos marinos poseedores de compuestos bioactivos que podrían ser empleados como medicamentos (Jha y Zi-Rong, 2004). En los últimos años se ha identificado una gran variedad de compuestos con actividades biológicas presentes en microorganismos marinos, fitoplancton, algas, esponjas, cnidarios, briozoos, moluscos, tunicados y equinodermos (Blunt et al., 2016). Los invertebrados marinos han demostrado ser una fuente importante de compuestos bioactivos (Yokota, 2005; Leal et al., 2012). Se ha logrado extraer una variedad de saponinas, glicolípidos, carotenoides, porfirinas, naftoquinonas, sulfatos de condroitina, glucosaminoglucanos, cereberosidos, lecitinas, péptidos, glicoproteínas, glicoesfingolípidos y ácidos grasos esenciales de equinodermos (Bordbar et al., 2011; Gomes et al., 2016).
Los pepinos de mar tienen la característica de poseer mecanismos de defensa que les permite sintetizar diversos metabolitos secundarios para protegerse contra infecciones microbianas y depredadores (Pawlik et al., 1995; Simmons et al., 2005). Los metabolitos de pepino de mar poseen propiedades antinflamatorias, analgésicas, antipiréticas, antibacterianas, antifúngicas, antivirales, anti-cancerígenas, así como otras actividades biológicas (Ridzwan et al., 1995; Haug et al., 2002; Dobretsov et al., 2009; Farjami et al., 2013; Mohammadizadeh et al., 2013; Dhinakaran y Lipton, 2014; Janakiram et al., 2015; Tripoteau et al., 2015).

Staphylococcus aureus es un patógeno que infecta a pacientes hospitalizados con disminución de la inmunidad y a las personas sanas inmunocompetentes (Elek, 1956) causando infecciones locales de la piel, nariz, uretra, vagina y tracto gastrointestinal (Shulman y Nahmias, 1972). Además, es un patógeno importante debido al aumento de su resistencia a los antibióticos (Lowy, 1998). Pseudomonas aeruginosa, patógeno opor- 
tunista, responsable de una amplia gama de infecciones, principalmente nosocomiales (Berthelot et al., 2005), y puede causar neumonías, infecciones del tracto urinario y bacteriemias (Ochoa et al., 2013). Se caracteriza por su resistencia intrínseca a diversas clases de antibióticos y a su capacidad de adquirir nuevos mecanismos de resistencia (Strateva y Yordanov, 2009; Roca, 2014). Vibrio alginolyticus es un patógeno de peces y moluscos bivalvos. En los peces causa septicemia, exoftalmia, opacidad corneal, ascitis, letargo, melanosis y úlceras. Está asociado con mortalidades masivas en larvas de moluscos bivalvos (Lee et al., 1996; Selvin y Lipton, 2003; Austin B y Austin D, 2007). En humanos se ha relacionado con infecciones de oído, tejidos blandos y heridas; además, presenta resistencia antibiótica (Horii et al., 2005). Es por ello la necesidad de descubrir nuevos antibióticos cuyo mecanismo de acción sea diferente a los convencionales (Da Costa et al., 2015).

Especies de pepino de mar como Holothuria leucospilota, Holothuria atra, Holothuria scabra, Bohadschia argus y Stichopus variegatus han demostrado poseer metabolitos con actividad antibacteriana, siendo estos extractos obtenidos a base de metanol, agua-metanol, acetato de etilo y cloroformo a partir de la pared corporal, gónadas, intestinos y fluido celómico. Estos extractos han sido confrontados a cepas bacterianas (Staphylococcus epidermidis, Proteus vulgaris, Shigella dysenteriae, Bacillus cereus, Escherichia coli, Salmonella typhimurium, S. aureus, P. aeruginosa) demostrando gran actividad antibacteriana (Farjami et al., 2013; Layson et al., 2014; Shakouri et al., 2014; Santos et al., 2015; Ebrahimi et al., 2018). Además se ha demostrado un efecto microbiostático de extractos de la pared corporal de H. leucospilota frente a E. coli, Salmonella typhi, S. aureus y $P$. aeruginosa (Adibpour et al., 2014).
En el Perú, existen aproximadamente 74 especies de pepino de mar (Hooker et al., 2013), de las cuales, las más abundantes a lo largo de la costa peruana son Pattalus mollis y Athyonidium chilensis (Prieto, 2010), en tanto que la pesquería se centra en $P$. mollis (Hooker et al., 2013). Por otro lado, existe una solo investigación relacionada a la evaluación anticoagulante de $P$. mollis (Zheng et al., 2019). Por lo expuesto, la presente investigación tuvo como objetivo identificar la actividad antibacteriana de extractos de tegumento, gónada y vísceras de $P$. mollis, demostrando que este equinodermo es una alternativa para el descubrimiento de compuestos antibacterianos sobre patógenos de interés como $P$. aeruginosa, $S$. aureus y $V$. alginolyticus.

\section{Materiales y Métodos}

\section{Recolección de Muestras}

Los especímenes de $P$. mollis fueron colectados mediante buceo en la zona de Concha Blanca y Chunco, frente al puerto de Pucusana (12²8'31.3"S - 76²4'49.9"O, Lima-Perú) durante 2016. Las muestras de $P$. mollis fueron colocadas en cajas isotérmicas con geles refrigerantes y trasladadas a las instalaciones del Instituto Tecnológico de la Producción (ITP), donde se almacenaron en congelación $\left(-20^{\circ} \mathrm{C}\right)$ hasta su tratamiento. La identificación taxonómica de la especie fue realizada por el Laboratorio de Biología y Sistemática de Invertebrados Marinos (Facultad de Ciencias Biológicas, Universidad Nacional Mayor de San Marcos, Lima).

\section{Procesamiento de Especímenes}

El material recolectado de $P$. mollis fue lavado con agua de mar y sus órganos internos (gónadas y vísceras) extraídos mediante una disección longitudinal de la zona ventral. Se homogenizaron hasta obtener una pasta, 


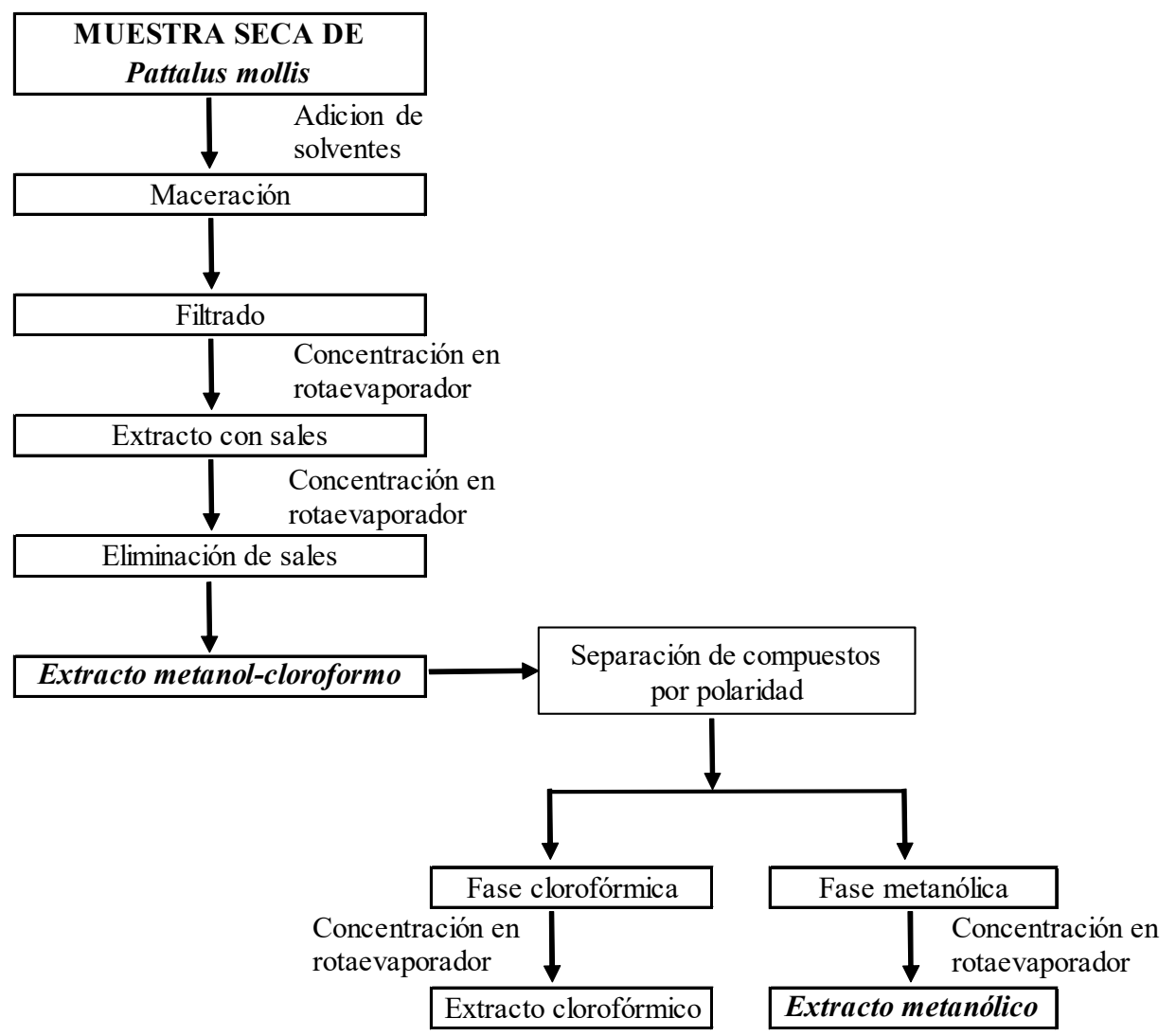

Figura 1. Diagrama para la obtención de los extractos de Pattalus mollis

la cual se secó a $60{ }^{\circ} \mathrm{C}$ en estufa (Memmert) hasta contener $10 \%$ de humedad y se molió hasta obtener un polvo fino. Las muestras fueron tamizadas para obtener material molido homogéneo. Finalmente se empacó al vacío y se almacenó en congelación $\left(-20^{\circ} \mathrm{C}\right)$.

\section{Obtención de Extractos}

\section{Extracto metanol-cloroformo (EMC)}

Los extractos se obtuvieron a partir de las muestras secas. La extracción se realizó con base a su polaridad según Abdallah e Ibrahim (2012) con algunas modificaciones. Se agregó a la muestra seca (50 g) una mezcla de solventes $(200 \mathrm{ml})$ de diferente polaridad: metanol $\left(\mathrm{CH}_{3} \mathrm{OH}\right)$ y cloroformo $\left(\mathrm{CHCl}_{3}\right)$ (en proporción 2:1 v/w). La mezcla de cada matriz con solvente fue puesta en agitación constante $(600 \mathrm{rpm})$ a temperatura ambiente por $1 \mathrm{~h}$. Los extractos se retiraron de agitación y se filtraron en papel Whatman $\mathrm{N} .^{\circ} 1$, haciendo este procedimiento por triplicado para tegumento y víscera y cuadriplicado para gónada. Los solventes fueron eliminados con un rotaevaporador (Heidolph) a $30{ }^{\circ} \mathrm{C}$ en completa oscuridad. Para eliminar las sales presentes se adicionó metanol y cloroformo (1:1), formándose un precipitado que se filtró en papel Whatman N. ${ }^{\circ} 1$. Se eliminó el solvente por rotaevaporación, obteniéndose un extracto metanol-cloroformo (EMC) (Figura 1). Los extractos se disolvieron en agua con dimetilsulfóxido (DMSO) y Tween 20. Finalmente se almacenó en congelación $\left(-20^{\circ} \mathrm{C}\right)$ hasta su evaluación. 


\section{Extracto metanólico (EM)}

El EM se obtuvo a partir del EMC mediante cloroformo y agua. El EMC (1 g) fue resuspendido en una mezcla de $35 \mathrm{ml}$ de metanol y $35 \mathrm{ml}$ de cloroformo, a la cual se adicionó $30 \mathrm{ml}$ de agua desionizada. Se agitó fuertemente durante 1 min y se dejó reposar. Esto fue repetido por tres veces. Se observó la formación de una fase apolar (cloroformo) y otra polar (metanol + agua). Cada fase fue separada por decantación. Seguidamente se procedió a concentrar a presión reducida obteniéndose los respectivos extractos metanólicos que fueron almacenados en congelación $\left(-20^{\circ} \mathrm{C}\right)$ hasta su evaluación. La concentración de los extractos se determinó mediante gravimetría.

\section{Microorganismos y Medios de Cultivo}

Se emplearon cepas bacterianas American Type Culture Collection (ATCC): P. aeruginosa ATCC 27853, V. alginolyticus ATCC 17749 y $S$. aureus ATCC 14777 de la colección del Laboratorio de Biotecnología del ITP. Las cepas bacterianas fueron verificadas mediante pruebas bioquímicas (Kaysner y De Paola, 1998; MacFaddin, 2000; Markey et al., 2013)

Se empleó el caldo Muller Hinton (CMH, Merck) y el agar Muller Hinton (AMH, Merck) a pH (7.2 \pm 0.2$)$, esterilizados a $121^{\circ} \mathrm{C}$ durante $15 \mathrm{~min}$. Los medios se suplementaron con $\mathrm{NaCl}$ al $3 \%$ para $V$. alginolyticus.

\section{Preparación de Inóculo}

Las cepas bacterianas fueron cultivadas durante la noche a $37{ }^{\circ} \mathrm{C}$, luego se centrifugaron durante $5 \mathrm{~min}$ a $1789 \mathrm{~g}$ y los pellets se resuspendieron en caldo hasta una densidad óptica de $0.5 \pm 0.02$ a $600 \mathrm{~nm}$ de absorbancia. Las unidades formadoras de colonias (UFC) se determinaron por recuento en placa. Finalmente, el inóculo se diluyó hasta la concentración de $1 \times 10^{5} \mathrm{UFC} / \mathrm{ml}$ (Sarker et al., 2007).

\section{Evaluación Antibacteriana}

Se determinó mediante la técnica de microdilución en caldo (CLSI, 2012), empleando placas de 96 pocillos para determinar la concentración mínima inhibitoria (CMI) y la concentración mínima bactericida (CMB). Se realizaron seis diluciones seriadas a partir de $250 \mathrm{mg} / \mathrm{ml}(125,62.5,31.25,15.63$, $7.81,3.90 \mathrm{mg} / \mathrm{ml})$. Se adicionaron en cada pocillo $90 \mu \mathrm{l}$ de cada extracto y se enfrentó con $10 \mu \mathrm{l}$ de inóculo bacteriano $\left(10^{5} \mathrm{UFC} / \mathrm{ml}\right)$. Se incubaron a $37^{\circ} \mathrm{C}$ durante $24 \mathrm{~h}$.

\section{Análisis Cualitativo}

Según la CLSI(2012), se consideró a la CMI como la mínima cantidad de extracto capaz de impedir el crecimiento de un microorganismo y a la CMB como la mínima cantidad de extracto capaz de destruir el 99.9\% de la cepa bacteriana. Para determinar el CMI y la CMB se realizó una siembra volumétrica después de la microdilución en caldo, inoculando $10 \mu \mathrm{l}$ de cada pocillo en AMH e incubando a $37^{\circ} \mathrm{C}$ durante $24 \mathrm{~h}$.

\section{Resultados}

Los resultados de la actividad antibacteriana de los extractos EMC y EM de $P$. mollis se presentan en los cuadros 1 y 2. Se observó que los extractos metanólicos de $P$. mollis poseen actividad antibacteriana frente a las tres bacterias evaluadas, en comparación de los EMC que no presentaron actividad antibacteriana.

El extracto metanólico de vísceras frente $P$. aeruginosa y $V$. alginolyticus presentó un efecto bacteriostático $(\mathrm{CMI}=$ $62.5 \mathrm{mg} / \mathrm{ml})$ y bactericida $(\mathrm{CMB}=125 \mathrm{mg} / \mathrm{ml})$, el extracto de gónada fue bacteriostático frente a $S$. aureus $(\mathrm{CMI}=62.5 \mathrm{mg} / \mathrm{ml})$ y bactericida sobre $S$. aureus y $V$. alginolyticus $(\mathrm{CMB}=125 \mathrm{mg} / \mathrm{ml})$. Por otro lado, se observó que el extracto de tegumento presentó menor inhibición bacteriana; sin embar- 
Cuadro 1. Actividad antibacteriana de los extractos metanol-cloroformo (EMC) y extractos metanólicos (EM) de Pattalus mollis frente a Pseudomonas aeruginosa, Staphylococcus aureus y Vibrio alginolyticus

\begin{tabular}{|c|c|c|c|c|}
\hline \multirow{2}{*}{ Matrices } & \multirow{2}{*}{ Solvente } & \multicolumn{3}{|c|}{ Actividad antibacteriana } \\
\hline & & P. aeruginosa & S. aureus & V. alginolyticus \\
\hline \multirow[t]{2}{*}{ Gónada } & EMC & - & - & - \\
\hline & EM & + & + & + \\
\hline \multirow[t]{2}{*}{ Tegumento } & EMC & - & - & - \\
\hline & EM & + & + & + \\
\hline \multirow[t]{2}{*}{ Víscera } & EMC & - & - & - \\
\hline & EM & + & + & + \\
\hline
\end{tabular}

(-) Sin actividad antibacteriana, (+) Con actividad antibacteriana

Cuadro 2. Concentración mínima inhibitoria (CMI) y concentración mínima bactericida (CMB) del extracto metanólico de vísceras de Pattalus mollis frente a Pseudomonas aeruginosa, Staphylococcus aureus y Vibrio alginolyticus

\begin{tabular}{|c|c|c|c|c|c|c|}
\hline \multirow{2}{*}{ Muestra } & \multicolumn{3}{|c|}{$\begin{array}{c}\mathrm{CMI} \\
(\mathrm{mg} / \mathrm{ml})\end{array}$} & \multicolumn{3}{|c|}{$\begin{array}{c}\mathrm{CMB} \\
(\mathrm{mg} / \mathrm{ml})\end{array}$} \\
\hline & $\begin{array}{c}P . \\
\text { aeruginosa }\end{array}$ & $\begin{array}{c}S . \\
\text { aureus }\end{array}$ & $\begin{array}{c}V \\
\text { alginolyticus }\end{array}$ & $\begin{array}{c}P . \\
\text { aeruginosa }\end{array}$ & $\begin{array}{c}S . \\
\text { aureus }\end{array}$ & $\begin{array}{c}V . \\
\text { alginolyticus }\end{array}$ \\
\hline Tegumento & 125 & 250 & 62.5 & 250 & 250 & 125 \\
\hline Gónada & $>125$ & 62.5 & $>62.5$ & 250 & 125 & 125 \\
\hline Víscera & 62.5 & 125 & 62.5 & 125 & 250 & 125 \\
\hline
\end{tabular}

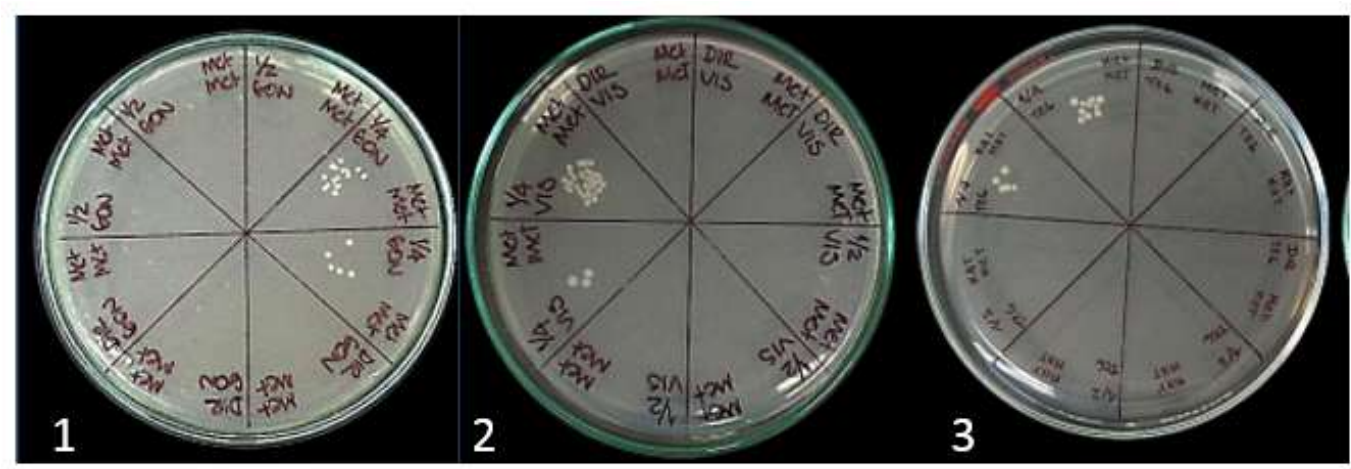

Figura 2. Efecto bactericida y bacteriostático de extractos metanólicos (1) de gónada de Pattalus mollis frente a Staphylococcus aureus, (2) de vísceras frente a Pseudomonas aeruginosa y efecto bactericida de extracto metanólico de (3) tegumento frente a Vibrio alginolyticus 
go, frente a $V$. alginolyticus presentó un efecto bacteriostático $(\mathrm{CMI}=62.5 \mathrm{mg} / \mathrm{ml})$ y bactericida $(\mathrm{CMB}=125 \mathrm{mg} / \mathrm{ml})$ (Figura 2$)$.

\section{Discusión}

Los resultados permiten afirmar que $P$. mollis, especie marina recolectada de las costas peruanas, es un organismo portador de sustancias bioactivas con actividad antibacteriana. La gran mayoría de investigaciones realizadas con extractos de pepinos de mar evidencian la actividad sobre bacterias grampositivas y gramnegativas como $E$. coli, S. dysenteriae, B. cereus, $S$. epidermidis, S. aureus, $P$. aeruginosa, $V$. parahaemolyticus, $V$. harveyi y $V$. alginolyticus (Villasin y Pomory, 2000; Manilal et al., 2010; Farjami et al., 2013; Layson et al., 2014; Shakouri et al., 2014). Esta actividad antibacteriana concuerda con los resultados del presente estudio, ya que los extractos de pepino de mar obtenidos inhibieron el crecimiento de $P$. aeruginosa ATCC 27853, $S$. aureus ATCC 14775 y $V$. alginolyticus ATCC 17749.

Ridzwan et al. (1995) evaluaron tres especies de pepino de mar, $H$. atra, $H$. scabra y $B$. argus, determinando que sus extractos metanólicos y lipídicos no poseen actividad antibacteriana. Del mismo modo, Santos et al. (2015) evaluando Stichopus regalis determinaron que sus extractos metanólicos no poseen actividad antibacteriana. Estos resultados difieren de los obtenidos con $P$. mollis en este estudio que demuestran que esta especie es un organismo poseedor de compuestos antibacterianos en tegumento, gónada y vísceras. Por otro lado, Ridzwan et al. (1995) realizaron comparaciones entre los extractos del tegumento y los órganos internos de $H$. atra determinando que el tegumento posee menos propiedades de inhibición frente a $S$. aureus, concordando con este estudio donde el tegumento de P. mollis presentó menor actividad (250 $\mathrm{mg} / \mathrm{ml}$ ) frente a $S$. aureus en comparación a las vísceras y gónada (CIM: 125 y $62.5 \mathrm{mg} / \mathrm{ml}$, respectivamente).

Los EMC en esta investigación no presentaron actividad antibacteriana frente a las tres bacterias patógenas evaluadas, al igual que en el estudio de Dobretsov et al. (2009), quienes evaluaron EMC de $H$. atra y $H$. edulis frente a $S$. aureus y $P$. aeruginosa. A diferencia del trabajo de Dobretsov et al. (2009), en este estudio se realizó una posterior separación de fases al EMC, lo cual permitió separar compuestos polares obteniendo un extracto metanólico que presentó actividad antibacteriana.

Farjami et al. (2013) probaron extractos de metanol, cloroformo y hexano del tegumento, gónadas e intestinos de $H$. leucospilota del Golfo Pérsico frente a $B$. subtilis, $S$. aureus (grampositivas) y $P$. aeruginosa (gramnegativa), demostrando que los extractos de cloroformo y hexano tuvieron actividad frente a las bacterias testadas, mientras que las concentraciones de extractos de metanol (polar) de gónadas e intestino no mostraron actividad antibacteriana frente a estas bacterias. En la presente investigación se ha demostrado que los extractos metanólicos obtenidos de $P$. mollis poseen, por lo menos, un compuesto bioactivo con actividad antibacteriana en gónadas, tegumento y vísceras, a diferencia del estudio de Farjami et al. (2013) donde $H$. leucospilota solo presentó actividad a partir del tegumento. Además, la actividad antibacteriana del tegumento de $H$. leucospilota solo se manifestó frente a bacterias Gram negativas, mientras que $P$. mollis demostró ser efectiva frente a ambos grupos bacterianos. Se podría inferir que no todos los pepinos de mar poseen componentes antibacterianos de amplio espectro.

Ebrahimi et al. (2018) evaluó la CMI de Holothuria parva determinando que el efecto inhibitorio varió de 100 a $250 \mathrm{mg} / \mathrm{ml}$ de los extractos metanólicos; resultados que concuerdan con los de este estudio demostrando que los compuestos de $P$. mollis mues- 
tran una potencial actividad antibacteriana y podrían ser un candidato novedoso para combatir enfermedades bacterianas.

\section{Conclusiones}

- Se describe por primera vez la actividad antibacteriana del pepino de mar Pattalus mollis proveniente de costas peruanas, estableciéndose que los extractos de gónada, tegumento y víscera poseen actividad antibacteriana.

- El extracto metanólico de $P$. mollis muestra actividad antibacteriana, por lo que puede constituir una fuente importante de compuestos bioactivos.

\section{Agradecimientos}

Se agradece al Programa Nacional de Innovación para la Competitividad y Productividad (Innóvate Perú) por financiar y permitir el desarrollo de este trabajo en el marco Convenio N. ${ }^{\circ} 302$ - INNOVATEPERUPIAP-2015.

\section{Literatura Citada}

1. Abdallah H, Ibrahim H. 2012. Antibacterial carotenoids of three Holothuria species in Hurghada, Egypt. Egyp J Aquatic Res 38: 185-194. doi: 10.1016/j.ejar.2013.01.004

2. Adibpour N, Nasr F, Nematpour F, Shakouri A, Ameri A. 2014. Antibacterial and antifungal activity of Holothuria leucospilota isolated from Persian Gulf and Oman Sea. Jundishapur J Microb 7: e8708. doi: 10.5812/jjm.8708

3. Austin B, Austin DA. 2007. Bacterial fish pathogens, disease of farmed and wild fish. $4^{\text {th }}$ ed. Godalming, UK: Springer Praxis. 552 p.

4. Berthelot P, Grattard F, Mallaval FO, Ros A, Lucht F, Pozzetto B. 2005. Épidémiologie des infections nosocomiales à Pseudomonas aeruginosa,
Burkholderia cepacia et Stenotrophomonas maltophilia. Pathol Biol 53: 341-348. doi: 10.1016/j.patbio.2004.09.006

5. Blunt JW, Copp BR, Keyzers RA, Munro MH, Prinsep MR. 2016. Marine natural products. Nat Prod Rep 33: 382-431. doi: 10.1039/C5NP00156K

6. Bordbar S, Anwar F, Saari N. 2011. High-value components and bioactives from sea cucumbers for functional foods. Mar Drugs 9: 1761-1805. doi: 10.3390/ md9101761

7. [CLSI] Clinical and Laboratory Standards Institute. 2012. Methods for dilution antimicrobial susceptibility tests for bacteria that grow aerobically; approved standard-Eighth edition. CLSI document M07-A8. [Internet]/ Available in: https://simpleshowoflove.weebly.com/ uploads/1/4/0/7/14073276/ agar_dilution_assay.pdf

8. Da Costa JP, Cova M, Ferreira $R$, Vitorino R. 2015. Antimicrobial peptides: an alternative for innovative medicines. Appl Microbiol Biotechnol 99: 20232040. doi: 10.1007/s00253-015-6375-x

9. Dhinakaran DI, Lipton AP. 2014. Studies on the bioactivity of Holothuria atra extracts collected from the South east coast of India International. J Biol Biological Sci 3: 6-11.

10. Dobretsov S, Al-Mammari IM, Soussi B. 2009. Bioactive compounds from Omani sea cucumbers. J Agric Marine Sci 14: 49-53.

11. Ebrahimi H, Vazirizadeh A, Nabipour I, Najafi A, Tajbakhsh S, Bahabadi M. 2018. In vitro study of antibacterial activities of ethanol, methanol and acetone extracts from sea cucumber Holothuria parva. Iran J Fish Sci 17: 542-551. doi: 10.22092/IJFS.2018.116472

12. Elek SD. 1956. Experimental Staphylococcal infections in the skin of man. Ann N Y Acad Sci 65: 85-90. doi: 10.1111/ j.1749-6632.1956.tb36626.x

13. Farjami B, Nematollahi MA, Moradi Y, Irajian G, Nazemi M, Ardebili A, Pournajaf A. 2013. Antibacterial 
activity of the sea cucumber Holothuria leucospilota. Int J Mol Clin Microbiol 3: 225-230. doi: 10.29244/jitkt.v9i2.19302

14. Gomes AR, Freitas AC, Duarte AC, Rocha-Santos TA. 2016. Echinoderms: a review of bioactive compounds with potential health effects. St Nat Prod Chem 49: 1-54. doi: 10.1016/B978-0-44463601-0.00001-6

15. Haug T, Kjuul AK, Styrvold OB, Sandsdalen E, Olsen ØM, Stensvåg K. 2002. Antibacterial activity in Strongylocentrotus droebachiensis (Echinoidea), Cucumaria frondosa (Holothuroidea), and Asterias rubens (Asteroidea). J Invertebr Pathol 81: 94-102. doi: 10.1016/S0022-2011(02)00153-2

16. Hooker Y, Prieto-Rios E, Solís-Marín FA. 2013. Echinoderms of Peru. In: Alvarado J, Solis-Marin F (eds). Echinoderm research and diversity in Latin America. Berlin: Springer, p 277 299. doi:10.1007/978-3-642-20051-9_8

17. Horii T, Morita M, Muramatsu H, Monji A, Miyagishima D, Kanno T, Maekawa M. 2005. Antibiotic resistance in Aeromonas hydrophila and Vibrio alginolyticus from a wound infection: a case report. J Trauma-Injury Infect Crit Care 58: 196-200. doi: 10.1097/01.TA.0000066381.33339.C0

18. Janakiram NB, Mohammed A, Rao $C V$. 2015. Sea cucumbers metabolites as potent anti-cancer agents. Mar Drugs 13: 2909-2923. doi: 10.3390/md13052909

19. Jha R, Zi-Rong X. 2004. Biomedical compounds from marine organisms. Mar Drugs 2: 123-146.

20. Kaysner CA, De Paola A. 1998. Vibrio cholera, Vibrio parahaemolyticus, Vibrio vulnificus and other Vibrio spp. In: Bacteriological analytical manual. $8^{\text {th }}$ ed. USA: Food and Drug Administration (FDA). p 901-927.

21. Layson RJ, Rodil MCA, Mojica ERE, Deocaris CC. 2014. Potential anticancer and anti-bacterial activities of Philippine echinoderm extracts. J Trop Life Sci 4: 175-181.
22. Leal MC, Madeira C, Brandão CA, Puga J, Calado R. 2012. Bioprospecting of marine invertebrates for new natural products a chemical and zoogeographical perspective. Molecules 17: 9842-9854. doi: 10.3390/molecules17089842

23. Lee KK, Yu SR, Chen FR, Yang TI, Liu PC. 1996. Virulence of Vibrio alginolyticus isolated from diseased tiger prawn, Penaeus monodon. Curr Microbiol 32: 229-231. doi: 10.1007/ s002849900041

24. Lowy FD. 1998. Staphylococcus aureus infections. N Engl J Med 339: 2025-2027. doi: 10.1056/NEJM199812313392716

25. MacFaddin JF. 2000. Biochemical tests for identification of medical bacteria. $3^{\text {rd }}$ ed. Philadelphia: Lippincott Williams \& Wilkins. $928 \mathrm{p}$.

26. Manilal A, Sujith S, Selvin J, Seghal Kiran G, Shakir C, Premnath Lipton A. 2010. Antimicrobial potential of marine organisms collected from the southwest coast of India against multiresistant human and shrimp pathogens. Scientia Marina 74: 287-296. doi: 10.3989/scimar.2010.74n2287

27. Markey B, Leonard F, Archambault M, Cullinae A, Maguire D. 2013. Clinical veterinary microbiology. $2^{\text {nd }} e d$. St. Louis, USA: Mosby Elsevier. 920 p.

28. Mohammadizadeh F, Ehsanpor M, Afkhami M, Mokhlesi A, Khazaali A, Montazeri S. 2013. Evaluation of antibacterial, antifungal and cytotoxic effects of Holothuria scabra from the north coast of the Persian Gulf. J Mycol Med 23: 225-229. doi: 10.1016/ j.mycmed.2013.08.002

29. Ochoa SA, López-Montiel F, Escalona G, Cruz-Córdova A, Dávila LB, López Martínez B, Xicohtencatl-Cortes J. 2013. Características patogénicas de cepas de Pseudomonas aeruginosa resistentes a carbapenémicos, asociadas con la formación de biopelículas. Bol Médico Hosp Infantil México 70(2): 136-150. 
30. Pawlik J, Chanas B, Toonen R, Fenical W. 1995. Defenses of Caribbean sponges against predatory reef fish. I. Chemical deterrency. Mar Ecol Prog Ser 127: 183-194. doi: 10.3354/ meps127183

31. Prieto E. 2010. Taxonomía de Holothuroidea (Echinodermata) del mar del Perú. Tesis de Biólogo. Lima: Univ. Nacional Mayor de San Marcos.79 p.

32. Ridzwan BH, Kaswandi MA, Azman Y, Fuad M. 1995. Screening for antibacterial agents in three species of sea cucumbers from coastal areas of Sabah. Gen Pharmacol-Vasc S 26: 15391543. doi: 10.1016/0306-3623(95)00041-0

33. Roca DAL. 2014. Pseudomonas aeruginosa: un adversario peligroso. Acta Bioquím Clín Latinoam 48: 465-474.

34. Santos R, Dias S, Pinteus S, Silva J, Alves C, Tecelão C, Pedrosa R. 2015. The biotechnological and seafood potential of Stichopus regalis. Adv Bioscie Biotechnol 6: 194-204. doi: 10.4236/abb.2015.63019

35. Sarker SD, Nahar L, Kumarasamy Y. 2007. Microtitre plate-based antibacterial assay incorporating resazurin as an indicator of cell growth, and its application in the in vitro antibacterial screening of phytochemicals. Methods 42: 321-324. doi: 10.1016/j.ymeth.2007.01 .006

36. Selvin J, Lipton AP. 2003. Vibrio alginolyticus associated with white spot disease of Penaeus monodon. Dis Aquat Org 57: 147-150. doi: 10.3354/ dao057147

37. Shakouri A, Nematpour F, Adibpour N, Ameri A. 2014. The investigation of anti-bacterial activity of Holothuria leucospilota sea cucumber extracts (body wall, guts and white strings) at Chabahar Bay in Oman Sea. Environ Studies Persian Gulf 1: 23-29.

38. Simmons T, Adrianasolo E, McPhail K, Flatt P, Gerwick WH. 2005. Marine natural products as anticancer drugs. Mol Cancer Ther 4: 333-342.

39. Shulman JA, Nahmias AJ. 1972. Staphylococcal infections: clinical aspects. In: Cohen JO (ed). The Staphylococci. New York: Wiley. p 457-482.

40. Strateva T, Yordanov D. 2009. Pseudomonas aeruginosa - a phenomenon of bacterial resistance. J Med Microbiol 58: 1133-1148. doi: 10.1099/ jmm.0.009142-0

41. Tripoteau L, Bedoux G, Gagnon J, Bourgougnon N. 2015. In vitro antiviral activities of enzymatic hydrolysates extracted from byproducts of the Atlantic holothurian Cucumaria frondosa. Process Biochem 50: 867-875. doi: 10.1016/j.procbio.2015.02.012

42. Villasin J, Pomory CM. 2000. Antibacterial activity of extracts from the body wall of Parastichopus parvimensis (Echinodermata: Holothuroidea). Fish Shellfish Immun 10: 465-467. doi: 10.1006/fsim.2000.0265

43. Yokota Y. 2005. Bioresources from echinoderms. In: Echinodermata. Berlin: Springer. p 251-266.

44. Zheng W, Zhou L, Lin L, Cai Y, Sun H, Zhao L, Gao N, et al. 2019. Physicochemical characteristics and anticoagulant activities of the polysaccharides from sea cucumber Pattalus mollis. Mar Drugs 29: 17(4). pii: E198. doi: 10.3390/ md17040198 